\title{
Reduced-fat spreads based on anhydrous milk fat and cellulose ethers
}

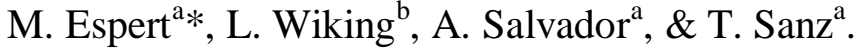

${ }^{a}$ Instituto de Agroquímica y Tecnología de Alimentos (CSIC),

Avda. Agustín Escardino 7,

46980 Paterna, Valencia, Spain

${ }^{\mathrm{b}}$ Department of Food Science, Aarhus University.

Blichers Allé 20, building F20.

8830 Tjele (Denmark).

*Corresponding author: mespert@ iata.csic.es

Tel: +34963900022

Fax: +34963636301 


\begin{abstract}
The design of reduced-fat spreads as a healthier alternative has been the subject of extensive attention lately. Reduced fat cellulose ether emulsions prepared using anhydrous milk fat (AMF) were compared with butter and pure AMF. The emulsions were composed of $47 \%$ AMF, water, and $2 \%$ cellulose ether. Three types of cellulose ethers were investigated: two methylcelluloses (A4M and MX) and one hydroxypropyl methylcellulose $(\mathrm{F} 4 \mathrm{M}))$. Structural behavior was analyzed by penetration test and small amplitude oscillatory rheology at $5{ }^{\circ} \mathrm{C}$ and $20^{\circ} \mathrm{C}$, and linked to the microstructure observation by confocal laser scanning microscopy. Melting behavior was examined by thermal analysis using differential scanning calorimetry. Cellulose ether type affected the crystal network formed and consequently the textural and rheological properties of the emulsions. The original compact structure of the AMF was softened by the presence of all cellulose types. All the AMF based emulsions showed a physical appearance similar to butter but with a softer consistency and spreadable at refrigeration and room temperature. The cellulose type MX provided the lowest viscoelasticity at refrigerated temperature. The emulsions could be used as a direct spreadable food or in applications that require plastic properties.
\end{abstract}

Keywords: anhydrous milk fat; cellulose ether; emulsion; microstructure; rheology. 


\section{Introduction}

In recent years, the consumer trend is based on demanding healthier foods, but retaining their technological and sensory characteristics. Butter, margarine and shortenings are fat sources widely used in the food industry due to the ability to provide specific structures and excellent sensory properties. Their high levels of fat (80\%) (Keogh, 2006) bring out the need for fat reduction alternatives, although large reductions in fat content alter the properties of food products (Bayarri, Taylor, \& Joanne, 2006; Mela, 1990; Drewnowski, 1992). One of the challenges of food manufacturers is to produce alternative low fat sources able to mimic the structural properties and sensory properties provided by conventional fat. Fat reduction and fat replacement are very complicated in foodstuffs which depend on the unique functional properties of such fats, such as the specific melting profiles in different applications, and the plasticity of laminating shortenings used in puff pastries.

Understanding the physical properties of fat is crucial to develop new fat sources and new products. Additives are used for the influence they have on crystallization, surface gloss, temperature stability, rheology, polymorphic stability, etc. (Smith, K.W., Bhaggan, K., Talbot, G., van Malssen, K.F., 2011). Addition of non-fat components modifies the physical behavior of the fat, especially the crystallization, which affect attributes such as spreadability, hardness, and mouthfeel (Weyland \& Hartel, 2008; Marangoni \& Narine, 2002).

Anhydrous Milk Fat (AMF) is a solid fat with functional properties such as plasticity, flavor and mouthfeel. It possess a wide diversity of fatty acids (FA) and triglyceride composition, including a broad thermal range of melting transitions (from $-40{ }^{\circ} \mathrm{C}$ to 40 $\left.{ }^{\circ} \mathrm{C}\right)$. It has been proven that the addition of other components on a solid fat as well as processing and storage conditions have important effects on final physicochemical properties (Kerr, Tombokan, Ghosh, \& Martini, 2011; Ronholt et al., 2014). The structural properties of AMF during temperature fluctuations (Buldo, Andersen, \& Wiking, 2013) and the effect of processing conditions of AMF with different melting fractions (Herrera \& Hartel, 2000a,b) were studied. Martini, Carelli, and Lee (2008) showed that the addition of waxes on AMF affect the crystallization behavior, modifying the texture and mouthfeel of system. The stability of o/w emulsion composed of AMF and soya bean oil stabilized by whey protein isolate was studied by Tippetts \& 
Martini (2009); they showed that maintaining constant the amount of emulsifier, the lipid droplet size and the amount of fat directly affect the stability of the emulsion.

Hydrocolloids have been widely employed in the development of low fat food. Addition of a polysaccharide in a fat emulsion contributes to replace some characteristics normally provided by the fat (McClements, 2015), and may also provide nutritional benefits associated with consumption of dietary fiber (Mudgil \& Barak, 2013). Recently oil/water cellulose ether emulsions have been claimed to be low fat alternative suitable to replace conventional fat in specific food products, such for example biscuits (Tarancón, Salvador, \& Sanz, 2013). The cellulose ethers act as emulsifier and stabilizer of the liquid oil and an emulsion with semisolid consistency suitable to replace conventional fat is obtained (Espert, Salvador \& Sanz, 2016; Espert et al., 2017). The limitation of this $\mathrm{o} / \mathrm{w}$ emulsions made from liquid oils is that they do not have the plastic properties and spreadability properties necessary in the production of many fat products.

Therefore, the aim of the present work is to study the texture, rheological, thermal and microstructure properties of reduced fat cellulose ether emulsions using anhydrous milk fat as solid fat source at room temperature. The obtained emulsions are expected to enlarge the possible applications of cellulose ether emulsions as fat substitutes in the food industry. The obtained properties are compared with pure AMF and commercial butter.

\section{Materials and methods}

\subsection{Raw material}

The emulsions were prepared with AMF, drinking water and three different cellulose ethers. AMF was supplied by ARLA Foods (Denmark) and cellulose ethers were provided by The Dow Chemical Co (Germany). Two type of methylcellulose with different degrees of methoxyl content (METHOCEL ${ }^{\mathrm{TM}} \mathrm{A} 4 \mathrm{M}$ and MX) and one type of hydroxypropyl methylcellulose (METHOCEL ${ }^{\mathrm{TM}}$ F4M) were employed. Butter (Lurpak) was supplied by Arla Foods (Denmark).

\subsection{Emulsion preparation}

The different emulsions were composed of AMF (47\% (w/w)), cellulose ether $(2 \%$ $(\mathrm{w} / \mathrm{w}))$ and water $(51 \%(\mathrm{w} / \mathrm{w}))$. The fat was melted at $65{ }^{\circ} \mathrm{C}$ and then kept at $40{ }^{\circ} \mathrm{C}$ to 
begin the preparation process. The cellulose ether was first dispersed in the fat using a stirrer (IKA Eurostar 20D) at low-medium speed for five minutes. The mixture was then hydrated by gradually adding water at $20{ }^{\circ} \mathrm{C}$ while the stirring speed was increased to $300 \mathrm{rpm}$. The $200 \mathrm{~g}$ mixture was then homogenized using an IKA T25 basic UltraTurrax with the dispersion tool S18N-19G, at $8000 \mathrm{rpm}$ for 1 minute and subsequently at $9500 \mathrm{rpm}$ for 2 minutes. Finally, the product was cooled and stored at $5{ }^{\circ} \mathrm{C}$.

\subsection{Texture measurements}

Evaluation of the emulsions hardness was carried out with a texture analyser (FTC TMS-Touch, Food Technology Corporation, USA) with a $25 \mathrm{~N}$ load cell. A penetration test was carried out at a speed of $0.5 \mathrm{~mm} / \mathrm{s}$ and a distance of $8 \mathrm{~mm}$, using a spherical probe (1/4' Sph. Stainless P/0.25S). Samples were placed in a cylindrical beakers (2 $\mathrm{cm}$ diameter) and were analyzed at $5{ }^{\circ} \mathrm{C}$ and $20{ }^{\circ} \mathrm{C}$, after 15 days of storage. The maximal force at the defined penetration distance was recorded and used as indicator for the relative hardness.

\subsection{Rheological behavior}

The rheological behavior was evaluated by oscillatory shear experiments performed on a controlled stress rheometer (AR-G2, TA Instruments (New Castle, DE, USA)) with a Peltier heating system, using $40 \mathrm{~mm}$ parallel plate geometry. Strain sweeps test were carried out from $2.00 \mathrm{E}-4 \%$ to $100 \%$ at a constant frequency of $1 \mathrm{~Hz}$ to measure the linear viscoelastic region (LVR). Frequency sweeps from 0.01 to $100 \mathrm{~Hz}$ at a stress wave amplitude inside the linear region were performed. Storage modulus $\left(G^{\prime}\right)$, loss modulus $\left(\mathrm{G}^{\prime \prime}\right)$ and loss tangent $\left(\tan \delta=\mathrm{G}^{\prime \prime} / \mathrm{G}^{\prime}\right)$ values were represented as a function of the angular frequency ( $\mathrm{rad} / \mathrm{s})$. All rheological tests were performed at $5{ }^{\circ} \mathrm{C}$ and $20^{\circ} \mathrm{C}$. The yield stress was estimated from the normalized plot of $\mathrm{G}^{\prime}$ taking as reference the average of its initial values at the lower torques reached by the rheometer. The yield stress was considered as the first stress value where the normalized G' differs from a value of 1 (Sanz, Fernández, Salvador, Muñoz, \& Fiszman, 2005).

\subsection{Microstructure analysis}

The microstructure of the emulsions was analysed by confocal laser scanning microscopy (CLSM) (Nikon C2, Nikon Instrument Inc, Tokyo, Japan) using 0.01\% Nile Red solution to stain fat. Sample was place in a glass slide after the solvent evaporated 
and was carefully covered by slide. The argon laser beam was set at $568 \mathrm{~nm}$ excitation. A 20x objective lens was used to acquire the images. Measurements were carried out at room temperature $\left(20 \pm 1{ }^{\circ} \mathrm{C}\right)$.

\subsection{Analysis of thermal behavior}

The thermal behavior of all emulsions was analyzed by Differential Scanning Calorimetry (DSC, Q2000 TA Instruments, UK). Of each sample, 10-15 mg was placed into a sealed aluminum pan. An empty sealed pan was used as reference. The samples were equilibrated at $5{ }^{\circ} \mathrm{C}$ and the temperature was increased to $75^{\circ} \mathrm{C}$ at a rate of 5 ${ }^{\circ} \mathrm{C} / \mathrm{min}$. The analysis was conducted after 3 and 15 days of storage $\left(5^{\circ} \mathrm{C}\right)$.

\subsection{Statistical Analysis}

The data obtained by texture, rheology and DSC were statistically analyzed by Analysis of variance (ANOVA) using XLSTAT statistical software (version 2010.5.02, Microsoft Excel@, Barcelona, Spain). Tukey test was used to assess the differences in mean values $(\mathrm{p}<0.05)$. Three replicates were performed with samples prepared on different days.

\section{Results and discussion}

\subsection{Large deformation properties: texture measurements}

The maximum penetration force obtained from the force/time profiles for the penetration test of the AMF cellulose ether spreads, pure $\mathrm{AMF}$ and butter, at $5{ }^{\circ} \mathrm{C}$ and $20{ }^{\circ} \mathrm{C}$ are shown in Table 1 . As expected, the maximum penetration force was higher at $5{ }^{\circ} \mathrm{C}$ than at $20{ }^{\circ} \mathrm{C}$ for all the systems. At $5{ }^{\circ} \mathrm{C}$, the AMF showed the highest hardness and irregularities in the force-distance curves, which reflect a brittle structure, as previously described by Buldo et al. (2013). The force values of butter were lower than for the pure $\mathrm{AMF}$ but similar to $\mathrm{F} 4 \mathrm{M}$ and $\mathrm{A} 4 \mathrm{M}$ spreads at $5^{\circ} \mathrm{C}$. The $\mathrm{MX}$ spread showed significantly the lowest force values, indicating a softer structure.

At room temperature $\left(20^{\circ} \mathrm{C}\right)$ a noticeable decrease in force values occurred, that can be explained by the melting behavior of most of triacylglycerides (TAGs) of AMF at this temperature (Viriato et al., 2019). AMF continued showing the highest hardness, however, the differences with butter became significantly lower than at $5{ }^{\circ} \mathrm{C}$. At $20{ }^{\circ} \mathrm{C}$, all the hydrocolloid-based spreads showed lower hardness than butter, being the F4M 
spread the closest to butter. At this temperature the texture profile of both A4M and MX were very similar. Therefore, incorporation of AMF as the fat phase of cellulose ethers emulsions provides a spread product softer than AMF, with a texture profile similar to butter, but with a $30 \%$ less fat.

\subsection{Linear viscoelastic properties}

The yield stress values calculated from the stress sweep curves are presented in table 2 . A high resistant to flow is observed, especially in AMF and butter controls which showed the highest yield stress values, followed by the A4M and F4M spreads. At $5{ }^{\circ} \mathrm{C}$ all the batters clearly showed higher yield stresses than at $20{ }^{\circ} \mathrm{C}$. At $5{ }^{\circ} \mathrm{C}$ all the hydrocolloid-based spreads showed lower resistance than the controls to the applied stress. This effect was more evident for MX spread, which showed the lowest value of yield stress. This pattern was supported by the mechanical spectra results, which are discussed below.

The viscoelastic behavior of the AMF cellulose ether spreads in comparison to pure $\mathrm{AMF}$ and butter at $5{ }^{\circ} \mathrm{C}$ and $20^{\circ} \mathrm{C}$ are shown in Figure $1 \mathrm{a}$ and $\mathrm{b}$, respectively. Tan $\delta$ as function of frequency is also shown in Figure 2. In addition, mean values of G', G', and $\tan \delta$ values at $1 \mathrm{~Hz}$ are shown in Table 2. A viscoelastic behavior with a predominance of the elastic or solid component $\left(G^{\prime}\right)$ versus the viscous or liquid component (G') was found in the available frequency sweep. The plateau area of the mechanical spectra was visualized in all the systems, with values of G' always higher than G', and low frequency dependence. The highest G' values, reflecting a harder structure, were found in AMF, followed very closely to butter and F4M spread, being the extend of the differences dependent on temperature. In all the systems the increase in temperature from 5 to $20^{\circ} \mathrm{C}$ produced a significant decrease in the viscoelastic functions $\mathrm{G}^{\prime}$ and $\mathrm{G}$ ', being the extent of the difference a function of the type of system. The chemical substitution of the cellulose ether affected the viscoelastic properties. At $5{ }^{\circ} \mathrm{C}, \mathrm{F} 4 \mathrm{M}$ spread showed the highest value of G' and the closest behavior to butter and AMF, on the other hand, MX emulsion presented the lowest values of G' and G', and the lowest viscoelasticity ( $\tan \delta$ closer to 1 ).

The increase in temperature up to $20^{\circ} \mathrm{C}$ reduced the values of $\mathrm{G}^{\prime}$ and $\mathrm{G}$ ', in all the systems, although values of $G^{\prime}$ continue to be higher than $G^{\prime}$ ' in all the frequency sweep studied. The lowest effect of the increase in temperature was found in the MX emulsion, where $\mathrm{G}^{\prime}$ and $\mathrm{G}^{\prime}{ }^{\prime}$ decreased at $20{ }^{\circ} \mathrm{C}$ but not so noticeable. In fact in the MX 
emulsion the predominancy of G' versus G', (degree of viscoelasticity) increase at 20 ${ }^{\circ} \mathrm{C}: \tan \delta\left(\mathrm{G}^{\prime} / \mathrm{G}^{\prime}\right)$ decrease from 0.62 at $5^{\circ} \mathrm{C}$ to 0.35 at $20^{\circ} \mathrm{C}$, indicating a higher predominancy of the solid properties at $20^{\circ} \mathrm{C}$ than at $5{ }^{\circ} \mathrm{C}$. On the other hand, the differences among F4M emulsion and butter and AMF became higher at $20{ }^{\circ} \mathrm{C}$, as the F4M decrease its viscoelasticity at $20{ }^{\circ} \mathrm{C}\left(\tan \delta\right.$ was 0.18 at $5{ }^{\circ} \mathrm{C}$ and 0.29 at $\left.20{ }^{\circ} \mathrm{C}\right)$ while the viscoelasticity of butter was not affected. Despite the lowest effect of temperature in the MX emulsion and $\mathrm{A} 4 \mathrm{M}$ emulsion, the $\mathrm{F} 4 \mathrm{M}$ continue showing the highest values of G' and G', and the highest viscoelasticity of all the cellulose types, and the closest behavior to butter, but the extent of the differences with $\mathrm{A} 4 \mathrm{M}$ and $\mathrm{MX}$ emulsions became lower at $20^{\circ} \mathrm{C}$ than at $5^{\circ} \mathrm{C}$.

\subsection{Microstructure analysis}

For a better understanding of the differences found in the texture and viscoelastic properties of the different systems, their microstructure was investigated. Confocal images of butter, AMF, and the different cellulose ether spreads are shown in Figure 3. The fat composition determines the amount of fat crystals, as well as the shape and the aggregation of the individual crystals into a network. Whether the fat is present as a continuous mass (like in anhydrous milk fat or butter oils) or in numerous small globules (e.g., as in milk or cream) has a considerable influence on its crystallization behavior (Huppertz \& Kelly, 2006).

Pure AMF shows a dense network made up from small spherulite crystals surrounded with liquid oil. For the most part, crystals are well-defined single entities (Kaufman et al., 2012), although it is visible the formation of crystals aggregates that establish connections between each other giving the system certain hardness. Butter shows a different microstructure characterized by a discontinuous structure of fat globules that consist of an outer crystalline layer composed of high melting fat, enclosing liquid oil inside (Heertje, 1993). It is generally assumed that the presence of fat globules in the microstructure of butter decreases the hardness of the product, as the continuous fat crystal network is interrupted by the globules (Buldo et al., 2013). The water droplets show the crystalline nature of interface in margarine, which is composed of a continuous network of fat crystals aggregates. As it is known, the presence of emulsifiers also affects the structure of the crystal network and the emulsion stability (Juriaanse \& Heertje, 1988; Ghosh \& Rousseau, 2011). The microstructure results confirm the highest hardness and viscoelasticity of AMF in comparison to butter. 
In the cellulose spreads a lower amount of fat is observed embedded in a continuous network formed by the hydrated hydrocolloid (black area). This result was expected as the concentration of fat in the cellulose ether emulsions was lower (47\%) than in butter $(80 \%)$ or pure AMF. Differences in the microstructure were found depending on the cellulose ether type, revealing differences in the emulsifying properties of the cellulose ethers. In the AMF-A4M spread (Figure 3d) the discontinuous fat phase is mainly composed of liquid fat that remained uncrystallized, and of a minor proportion of diffuse crystals (black shadow), smaller in size than the crystals of the AMF control. In the AMF-MX spread (Figure 3e), liquid fat was uniformly distributed in spheroidal globules and low level of crystallization is observed and the observed crystals are the smallest in size. This microstructure explains the lowest firmness and the lowest values of the viscoelastic functions found in the MX spreads, as smaller crystals form weaker links and these result in a decrease in viscoelasticity (Herrera \& Hartel, 2000b). AMFF4M spread (Figure 3f) shows a different microstructure, which reflects is harder structure in comparison to the other cellulose spreads. Fat appears uniformly distributed in the background, forming a continuous phase. Apparently a partial phase inversion may have occurred. More dense crystalline structure was observed. Crystal shape is affected by the presence of the cellulose ether network, producing larger crystals compared with AMF control. Also large aggregates are present in the structure; this could explain the highest hardness values, since the hardness of a spread depends on the amount of fat crystals (Juriaanse \& Heertje, 1988).

\subsection{Thermal behavior}

Structural properties of plastic fats are strongly affected by the thermal properties of the crystal network formed by the fat. In particular, the melting point is one of the factors which big influence in the functional behavior of fat-based products. Melting characteristics have been related to flavor release and consumer perception. Keogh (2006) suggested that the melting point of fat used for spreads should not exceed mouth temperature, as an unpleasant waxy effect starts to develop above this temperature. The melting behavior of the different systems monitored by DSC is shown in Figure 4. The medium melting fraction (MMF) (from $10{ }^{\circ} \mathrm{C}$ to $19{ }^{\circ} \mathrm{C}$ ) and the high melting fraction (HMF) (above $20{ }^{\circ} \mathrm{C}$ ) typical of AMF (Deffense, 1993; Tomaszewska-Gras, 2016) are observed in all AMF spreads. The melting parameters are summarized in Table 3. In the MMF no significant differences were found in the onset temperature 
among the different samples, although the peak temperature in this fraction was higher in all the cellulose spreads in comparison to AMF control, which indicates a delay in melting temperature. The main difference was observed in the enthalpy values $(\Delta H)$, which was significantly higher in the pure AMF. Either the presence of the hydrocolloid-water network and/or the lower proportion of fat in the cellulose spreads reduced the original compact structure of AMF, leading to a lower area of the MMF peak. The AMF-F4M spread showed higher area values than the other cellulose spreads, which can be attributed to the higher degree of crystalline structure as visualized in the microstructure analysis in this type of cellulose spread.

The storage conditions did not reveal a high impact on the fat crystal network in any of the AMF systems. Similar exothermic peaks were found in all spreads, indicating no significant changes in fat melting behavior through storage time (Table 4).

\section{Conclusions}

This study demonstrated that it is possible to obtain reduced-fat spreads based on cellulose ethers and AMF. The quality of the spreads depended on the type of cellulose ether, since the structure of continuous phase impacted significantly on the morphology of the fat crystals and consequently on the structural and thermal properties. The original compact structure of AMF was reduced in the cellulose ether emulsions, either by the presence of the hydrocolloid network or by the lower proportion of fat, providing softer and spreadable systems. Moreover, it was observed that the presence of cellulose caused a delay in the melting temperature of the fat, and the storage conditions did not reveal a high impact on the crystal network.

These emulsions allows the development of a reduced-fat product with a similar appearance to butter but softer and spreadable at refrigeration $\left(5{ }^{\circ} \mathrm{C}\right)$ and room temperature $\left(20^{\circ} \mathrm{C}\right)$ and could have a great potential as reduced-fat spreadable products, as well as for the manufacturing of more complex foods that require a fat source with plastic properties, avoiding the use of chemical modification methods.

\section{Acknowledgements}

The authors are grateful to Ministry of Economy and Competitiveness of the Spanish Government for financial support (Project AGL2015-68923-C2-1-R). The authors are also thankful to the University of Aarhus (Denmark) for financial support for mobility 
through the Graduate School of Science and Technology (GSST) PhD grant awarded to author M. Espert.

\section{References}

Bayarri, S., Taylor, A.J., \& Hort, J. (2006). The role of fat in flavor perception: effect of partition and viscosity in model emulsions. Journal of Agriculture and Food Chemistry, 54(23), 8862-8868.

Buldo, P., Andersen, U., \& Wiking, L. (2013). Microstructure and material properties of milk fat systems during temperature fluctuations. Food Biophysics, 8(4), 262-272.

Deffense, E. (1993). Milk fat fractionation today: a review. Journal of the American Oil Chemists' Society, 70(12), 1193-1201.

Drewnowski, A. (1992). Sensory properties of fats and fat replacements. Nutrition Reviews, 50(4), 17-20.

Espert M., Salvador, A., \& Sanz, T. (2016). In vitro digestibility of highly concentrated methylcellulose O/W emulsions: rheological and structural changes. Food and Function, 7, 3933-3942.

Espert, M., Borreani, J., Hernando, I., Quiles, A., Salvador, A., \& Sanz, T. (2017). Relationship between cellulose chemical substitution, structure and fat digestion in o/w emulsions. Food Hydrocolloids, 69, 76-85.

Ghosh, S., \& Rousseau, D. (2011). Fat crystals and water-in-oil emulsion stability. Current opinion in Colloid \& Interface Science, 16, 421-431.

Heertje, I. (1993). Microstructural studies in fat research. Food Structure, 12, 77-94.

Herrera, M.L., \& Hartel, R.W. (2000a). Effect of processing conditions on physical properties of a milk fat model system: Rheology. Journal of the American Oil Chemists' Society, 77(11), 1189-1196.

Herrera, M.L., \& Hartel, R.W. (2000b). Effect of processing conditions on physical properties of a milk fat model system: Microstructure. Journal of the American Oil Chemists' Society, 77(11), 1197-1205.

Huppertz, T. \& Kelly, A.L. (2006). Physical Chemistry of Milk Fat Globules. In F. Fox and P. L. H. McSweeney (Eds), Advanced Dairy Chemistry, Vol. 2: Lipids, 3rd ed. Springer, New York, pp 173-212.

Juriaanse, a.c., \& Heertje, I. (1988). Microstructure of shortenings, margarine and butter- A review. Food Structure, 7(2), 181-188. 
Keogh, M.K. (2006). Chemistry and technology of butter and milk fat spreads. In P.F. Fox \& P.L.H. McSweeney (Eds.), Advanced Dairy Chemistry, vol. 2: Lipids (pp. 333-363). New York: Springer.

Kerr, R.M., Tombokan, X., Ghosh, S., \& Martini, S. (2011). Crystallization behavior of anhydrous milk fat-sunflower oil wax blends. Journal of Agricultural and Food Chemistry, 59, 2689-2695.

Marangoni, A.G., \& Narine, S.S. (2002). Identifying key structural indicators of mechanical strength in networks of fat crystals. Food Research International, 35(10), 957-969.

Martini, S., Carelli, A.A., \& Lee, J. (2008). Effect of the addition of waxes on the crystallization behavior of anhydrous milk fat. Journal of the American Oil Chemists' Society, 85(12), 1097-1104.

McClements, D.J., (2015). Reduced-fat foods: the complex science of developing dietbased strategies for tackling overweight and obesity. Advances in Nutrition, 6(3), $338 \mathrm{~S}-352 \mathrm{~S}$.

Mela, D.J. (1990). Sensory preferences for fats: What, who, why?. Food Quality and Preference, 2(2), 95-101.

Mudgil, D., \& Barak, S. (2013). Composition, properties and health benefits of indigestible carbohydrate polymers as dietary fiber: A review. International Journal of Biological Macromolecules, 61, 1-6.

Ronholt, S., Buldo, P., Mortensen, K., Andersen, U., Knudsen, J.C., \& Lars Wiking. (2014). The effect of butter grains on physical properties of butter-like emulsions. Journal of Dairy Science, 97(4), 1929-1938.

Sanz, T., Fernández, M. A., Salvador, A., Muñoz, J., \& Fiszman, S. M. (2005). Thermogelation properties of methylcellulose (MC) and their effect on a batter formula. Food Hydrocolloids, 19(1), 141-147.

Smith, K.W., Bhaggan, K., Talbot, G., van Malssen, K.F. (2011). Crystallization of fats: influence of minor components and additives. Journal of the American Oil Chemists' Society, 88(8), 1085-1101.

Tarancón, P., Salvador, A., \& Sanz, T. (2013). Sunflower oil-water-cellulose ether emulsions as trans-fatty acid-free fat replacers in biscuits: texture and acceptability study. Food and Bioprocess Technology, 6(9), 2389-2398. 
Tippetts, M., \& Martini, S. (2009). Effect of oil content and processing conditions on the thermal behavior and physicochemical stability of oil-in-water emulsions. International Journal of Food Science and Technology, 44, 206-215.

Tomaszewska-Gras, J. (2013). Melting and crystallization DSC profiles of milk fat depending on selected factors. Journal of Thermal Analysis and Calorimetry, 113(1), 199-208.

Viriato, R. L. S., de Souza Queirós, M., Neves, M. I. L., Ribeiro, A. P. B., \& Gigante, M. L. (2019). Improvement in the functionality of spreads based on milk fat by the addition of low melting triacylglycerols. Food Research International, 120, 432-440.

Weyland M., \& Hartel, R.W. (2008). Emulsifiers in Confectionery. In G.L. Hasenhuettl, \& R.W. Hartel (Eds), Food Emulsifiers and Their Applications (pp 285-305). New York: Springer. 


\section{TABLES}

Table 1. Maximum force values of the different anhydrous milk fat (AMF) based emulsions and controls.

Sample $\quad$ Maximum Force (N)

\begin{tabular}{lcc} 
& $\mathbf{5}^{\circ} \mathbf{C}$ & $\mathbf{2 0}^{\circ} \mathbf{C}$ \\
\hline AMF & $34.28^{\mathrm{a}}$ & $3.15^{\mathrm{a}}$ \\
BUTTER & $12.41^{\mathrm{b}}$ & $2.86^{\mathrm{a}}$ \\
$\mathrm{AMF}+\mathrm{F} 4 \mathrm{M}$ & $12.14^{\mathrm{b}}$ & $1.66^{\mathrm{b}}$ \\
$\mathrm{AMF}+\mathrm{A} 4 \mathrm{M}$ & $11.31^{\mathrm{b}}$ & $0.84^{\mathrm{bc}}$ \\
$\mathrm{AMF}+\mathrm{MX}$ & $1.02^{\mathrm{c}}$ & $0.37^{\mathrm{c}}$
\end{tabular}

abc Values in the same column with the same letter are not statistically different $(\mathrm{P}<0.05)$ according to Tukey's test. 
Table 2. G', G', $\tan \delta$ (at 1Hz) and yield stress values of AMF emulsions and controls at $5^{\circ} \mathrm{C}$ and $20^{\circ} \mathrm{C}$.

\begin{tabular}{|c|c|c|c|c|c|c|c|c|}
\hline \multirow[b]{2}{*}{ Sample } & \multicolumn{4}{|c|}{$5^{\circ} \mathbf{C}$} & \multicolumn{4}{|c|}{$20{ }^{\circ} \mathrm{C}$} \\
\hline & $\begin{array}{c}\mathbf{G}^{\prime} \\
(\mathbf{P a})\end{array}$ & $\begin{array}{c}\mathbf{G}^{\prime \prime} \\
(\mathbf{P a})\end{array}$ & $\tan \delta$ & $\begin{array}{c}\text { Yield } \\
\text { stress } \\
(\mathrm{Pa}) \\
\end{array}$ & $\begin{array}{c}\mathbf{G}^{\prime} \\
(\mathbf{P a})\end{array}$ & $\begin{array}{c}\mathbf{G}^{\prime \prime} \\
(\mathbf{P a})\end{array}$ & $\tan \delta$ & $\begin{array}{c}\text { Yield } \\
\text { stress } \\
(\mathrm{Pa}) \\
\end{array}$ \\
\hline AMF control & $4855000^{\mathrm{a}}$ & $882200^{\mathrm{a}}$ & $0.18^{\mathrm{b}}$ & $4380^{\mathrm{a}}$ & $338900^{\mathrm{a}}$ & $39220^{\mathrm{a}}$ & $0.11^{\mathrm{d}}$ & $2733^{\mathrm{a}}$ \\
\hline Butter control & $3485000^{\mathrm{b}}$ & $554500^{\mathrm{b}}$ & $0.16^{\mathrm{b}}$ & $3404^{b}$ & $244500^{b}$ & $36360^{\mathrm{a}}$ & $0.15^{\mathrm{cd}}$ & $1830^{\mathrm{b}}$ \\
\hline $\mathrm{AMF}+\mathrm{F} 4 \mathrm{M}$ & $2202000^{c}$ & $399100^{\mathrm{bc}}$ & $0.18^{\mathrm{b}}$ & $2929^{c}$ & $67910^{c}$ & $19535^{\mathrm{b}}$ & $0.29^{\mathrm{bc}}$ & $14.19^{c}$ \\
\hline$A M F+A 4 M$ & $668050^{\mathrm{d}}$ & $267620^{c}$ & $0.40^{\mathrm{ab}}$ & $2565^{\mathrm{c}}$ & $29750^{d}$ & $12305^{\mathrm{c}}$ & $0.41^{\mathrm{a}}$ & $8.90^{\mathrm{d}}$ \\
\hline $\mathbf{A M F}+\mathbf{M X}$ & $57815^{\mathrm{e}}$ & $35610^{\mathrm{d}}$ & $0.62^{\mathrm{a}}$ & $41.94^{\mathrm{d}}$ & $33950^{\mathrm{d}}$ & $11825^{\mathrm{c}}$ & $0.35^{\mathrm{ab}}$ & $18.70^{\mathrm{c}}$ \\
\hline
\end{tabular}

${ }^{\text {abcd }}$ Means with different letters within the same column are significantly different $(\mathrm{p}<0.05)$ according to Tukey's test. 
Table 3. Thermal parameters of the different AMF based spreads and controls at 3 days.

\begin{tabular}{|c|c|c|c|c|c|c|}
\hline & & $\begin{array}{c}\text { Start } \\
{ }^{\circ} \mathrm{C}\end{array}$ & $\begin{array}{c}\text { Onset } \\
{ }^{\circ} \mathrm{C} \\
\end{array}$ & $\begin{array}{c}\text { Maximum } \\
{ }^{\circ} \mathrm{C} \\
\end{array}$ & $\begin{array}{c}\text { Stop } \\
{ }^{\circ} \mathrm{C} \\
\end{array}$ & $\begin{array}{c}\text { Area } \\
\mathrm{J} / \mathrm{g}\end{array}$ \\
\hline \multirow{4}{*}{$\sum_{\sum}^{E}$} & AMF control & $9.25^{\mathrm{a}}$ & $9.31^{\mathrm{a}}$ & $14.37^{b}$ & $20.81^{\mathrm{a}}$ & $12.94^{\mathrm{a}}$ \\
\hline & A4M & $8.90^{\mathrm{ab}}$ & $9.16^{\mathrm{a}}$ & $15.07^{\mathrm{ab}}$ & $20.03^{\mathrm{a}}$ & $7.61^{\mathrm{b}}$ \\
\hline & MX & $8.11^{\mathrm{b}}$ & $9.13^{\mathrm{a}}$ & $15.02^{\mathrm{ab}}$ & $19.11^{\mathrm{a}}$ & $7.76^{b}$ \\
\hline & F4M & $8.70^{\mathrm{ab}}$ & $9.25^{\mathrm{a}}$ & $15.33^{\mathrm{a}}$ & $19.64^{\mathrm{a}}$ & $8.53^{b}$ \\
\hline
\end{tabular}

$\begin{array}{cccccc}\text { AMF Control } & 20.55^{\mathrm{b}} & 22.96^{\mathrm{b}} & 32.57^{\mathrm{ab}} & 36.52^{\mathrm{c}} & 19.10^{\mathrm{a}} \\ \mathbf{A 4 M} & 22.48^{\mathrm{ab}} & 23.88^{\mathrm{ab}} & 32.28^{\mathrm{b}} & 39.00^{\mathrm{b}} & 7.53^{\mathrm{bc}} \\ \mathbf{M X} & 22.72^{\mathrm{ab}} & 23.89^{\mathrm{ab}} & 32.60^{\mathrm{ab}} & 40.75^{\mathrm{a}} & 8.44^{\mathrm{b}} \\ \mathbf{F 4 M} & 24.02^{\mathrm{a}} & 24.35^{\mathrm{a}} & 33.32^{\mathrm{a}} & 39.94^{\mathrm{a}} & 6.958^{\mathrm{c}}\end{array}$

${ }^{\text {abcd }}$ For each melting fraction, values in the same column with the same letter are not statistically different $(P<0.05)$ according to Tukey's test.

MMF: medium melting fraction

HMF: high melting fraction 
Table 4. Thermal parameters of the different AMF based spreads at 15 days.

\begin{tabular}{|c|c|c|c|c|c|c|}
\hline & & $\begin{array}{c}\text { Start } \\
{ }^{\circ} \mathrm{C} \\
\end{array}$ & $\begin{array}{c}\text { Onset } \\
{ }^{\circ} \mathrm{C} \\
\end{array}$ & $\begin{array}{c}\text { Maximum } \\
{ }^{\circ} \mathrm{C} \\
\end{array}$ & $\begin{array}{c}\text { Stop } \\
{ }^{\circ} \mathrm{C} \\
\end{array}$ & $\begin{array}{c}\text { Area } \\
\mathrm{J} / \mathrm{g}\end{array}$ \\
\hline \multirow{4}{*}{$\sum_{\Sigma}^{5}$} & AMF control & $9.25^{\mathrm{a}}$ & $9.31^{\mathrm{a}}$ & $14.37^{b}$ & $20.81^{\mathrm{a}}$ & $12.94^{\mathrm{a}}$ \\
\hline & A4M & $8.74^{\mathrm{a}}$ & $8.94^{\mathrm{a}}$ & $15.25^{\mathrm{ab}}$ & $19.97^{\mathrm{a}}$ & $9.58^{\mathrm{ab}}$ \\
\hline & MX & $8.71^{\mathrm{a}}$ & $8.72^{\mathrm{a}}$ & $16.45^{\mathrm{ab}}$ & $21.61^{\mathrm{a}}$ & $7.98^{\mathrm{b}}$ \\
\hline & F4M & $9.40^{\mathrm{a}}$ & $12.25^{\mathrm{a}}$ & $16.89^{\mathrm{a}}$ & $21.69^{\mathrm{a}}$ & $9.26^{\mathrm{b}}$ \\
\hline \multirow{4}{*}{$\sum$} & AMF control & $20.55^{\mathrm{b}}$ & $22.96^{\mathrm{a}}$ & $32.57^{\mathrm{a}}$ & $36.52^{\mathrm{a}}$ & $19.10^{\mathrm{a}}$ \\
\hline & A4M & $23.20^{\mathrm{a}}$ & $24.22^{\mathrm{a}}$ & $32.40^{\mathrm{a}}$ & $39.12^{\mathrm{a}}$ & $8.48^{\mathrm{b}}$ \\
\hline & MX & $22.90^{\mathrm{a}}$ & $23.94^{\mathrm{a}}$ & $32.70^{\mathrm{a}}$ & $39.41^{\mathrm{a}}$ & $7.11^{\mathrm{b}}$ \\
\hline & F4M & $23.63^{\mathrm{a}}$ & $24.76^{\mathrm{a}}$ & $33.83^{\mathrm{a}}$ & $38.71^{\mathrm{a}}$ & $7.07^{\mathrm{b}}$ \\
\hline \multicolumn{7}{|c|}{$\begin{array}{l}{ }^{a b} \text { For each melting fraction, values in the same column with the same letter are not statistically } \\
\text { different }(\mathrm{P}<0.05) \text { according to Tukey's test. }\end{array}$} \\
\hline \multicolumn{7}{|c|}{ MMF: medium melting fraction } \\
\hline \multicolumn{7}{|c|}{ HMF: high melting fraction } \\
\hline
\end{tabular}




\section{FIGURE LEGENDS}

Figure 1. G' and G', as function of frequency of $47 \%$ AMF emulsions and AMF and butter controls at $5^{\circ} \mathrm{C}\left(\right.$ a) and $20^{\circ} \mathrm{C}($ b).

Figure 2. Tan $\delta$ as function of frequency of $47 \% \mathrm{AMF}$ emulsions and $\mathrm{AMF}$ and butter controls at $5^{\circ} \mathrm{C}$ (a) and $20^{\circ} \mathrm{C}($ b).

Figure 3. Confocal laser scanning microscopy images of the different systems: AMF (a), Butter (b), AMF+A4M emulsion (c), AMF+MX emulsion (d) and $\mathrm{AMF}+\mathrm{F} 4 \mathrm{M}$ emulsion (e).

Figure 4. Differential scanning calorimetry melting curves of AMF spreads at 3 days (a) and 15 days (b) of storage at $5^{\circ} \mathrm{C}$. 


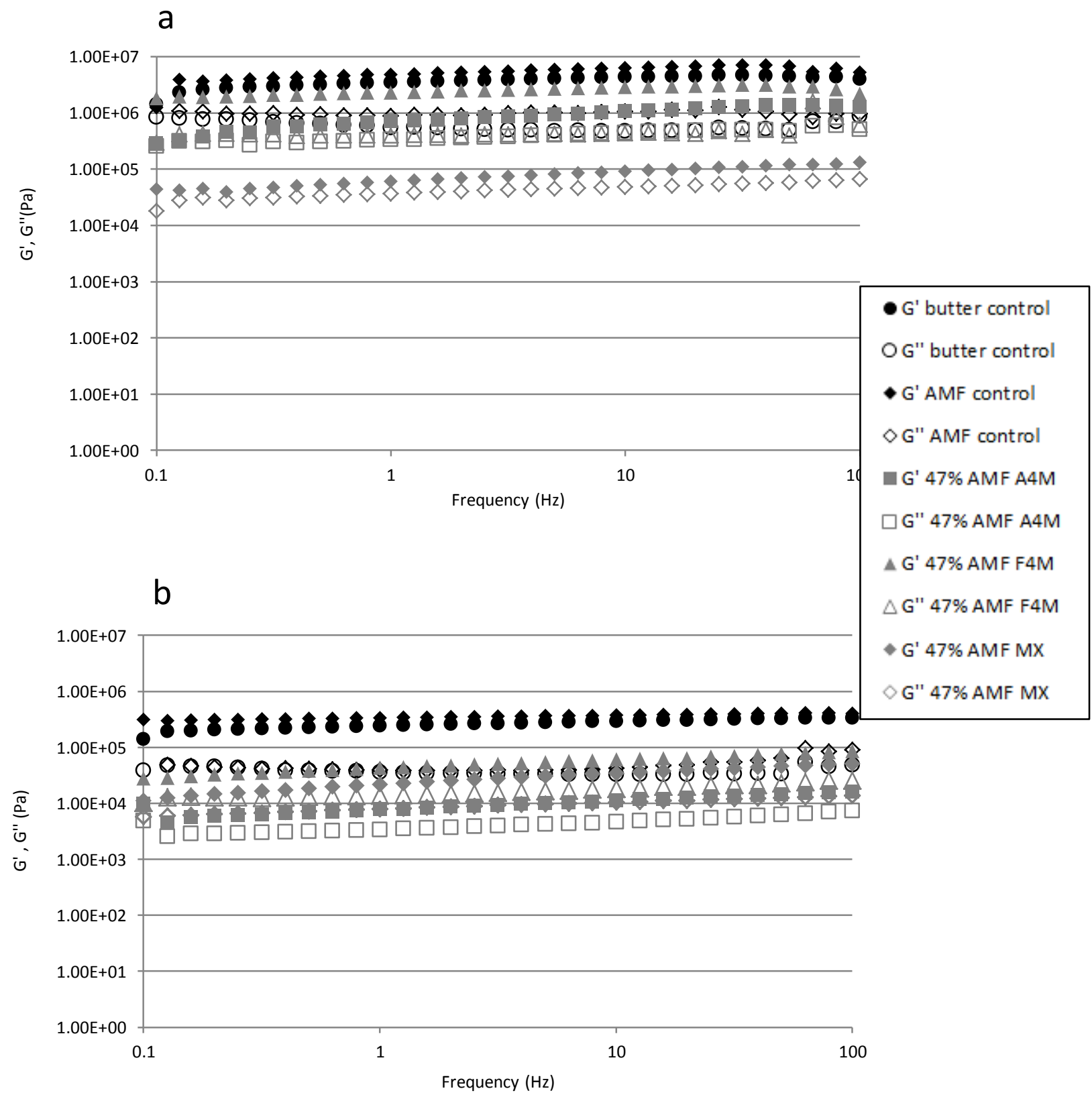

Figure 1. G' and G', as function of frequency of $47 \%$ AMF emulsions and AMF and butter controls at $5^{\circ} \mathrm{C}$ (a) and $20^{\circ} \mathrm{C}($ b). 


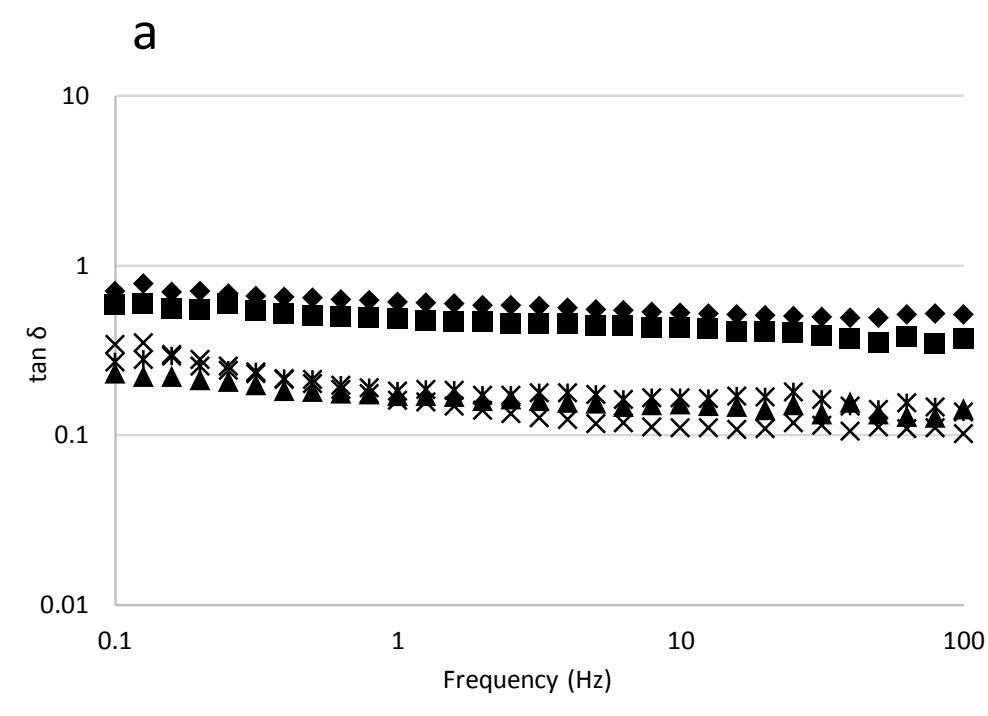

* AMF control

$\times$ Butter control

b

- $\mathrm{AMF}+\mathrm{A} 4 \mathrm{M}$

- AMF + MX

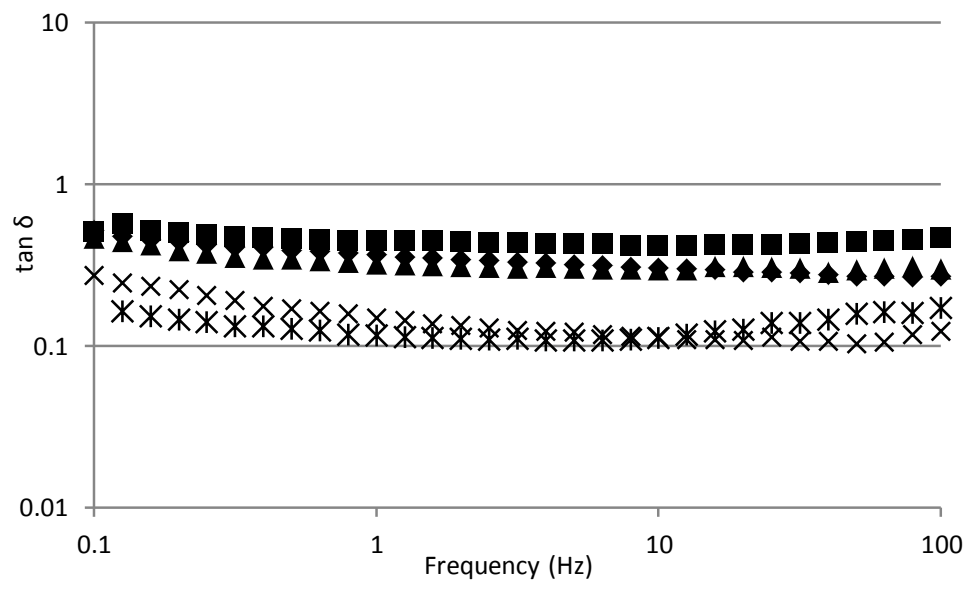

$\Delta \mathrm{AMF}+\mathrm{F} 4 \mathrm{M}$

Figure 2. Tan $\delta$ as function of frequency of $47 \%$ AMF emulsions and AMF and butter controls at $5^{\circ} \mathrm{C}$ (a) and $20^{\circ} \mathrm{C} \mathrm{(b).}$ 

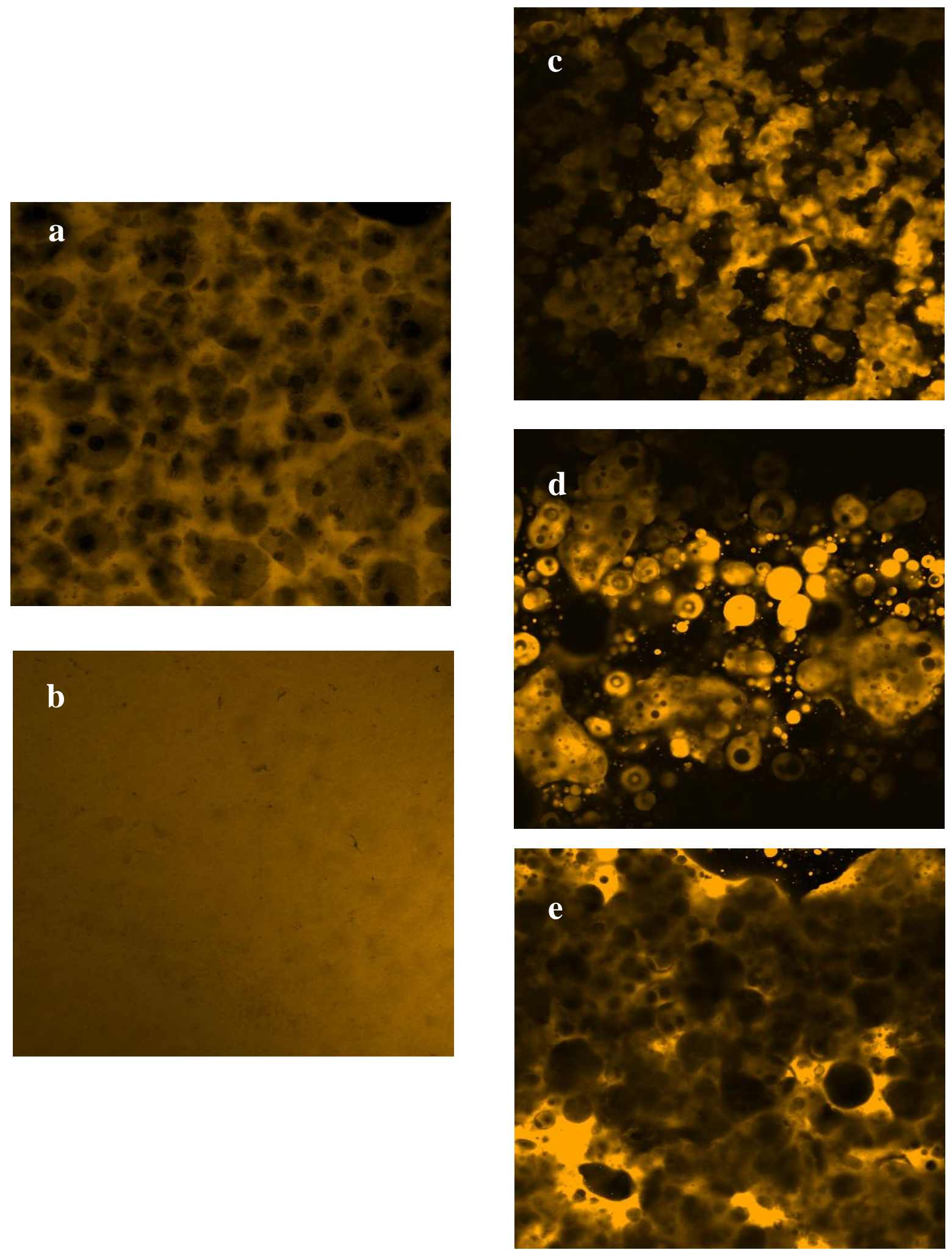

Figure 3. Confocal laser scanning microscopy images of the different systems: AMF (a), butter (b), AMF + A4M emulsion (c), AMF + MX emulsion (d) and AMF + F4M emulsion (e). 

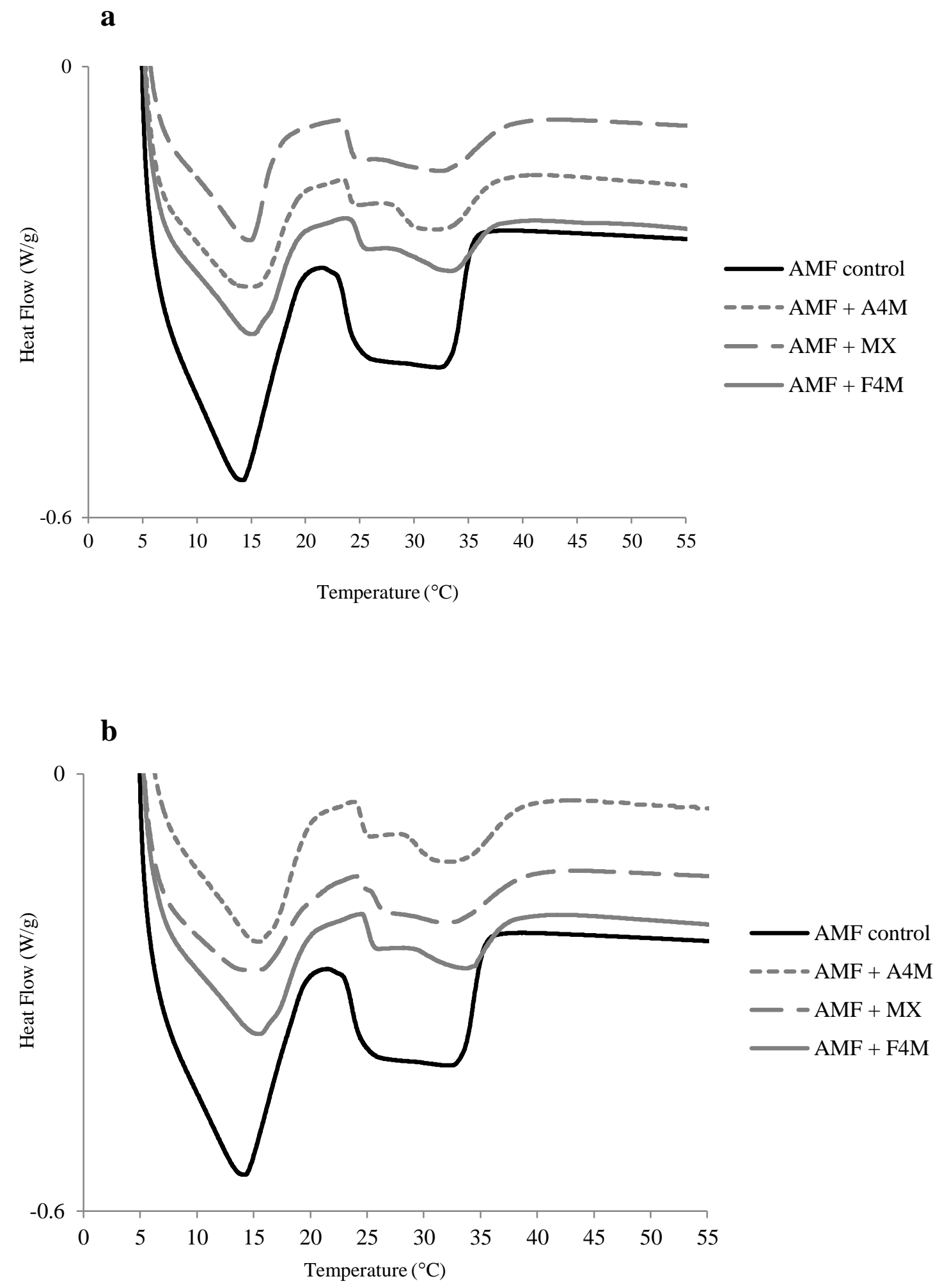

Figure 4. Differential scanning calorimetry melting curves of AMF spreads at 3 days (a) and 15 days (b) of storage at $5^{\circ} \mathrm{C}$. 